Bangladesh Journal of Neuroscience 2019; Vol. 35 (1): 10-13

\title{
Demographic Pattern of Alzheimer's Disease in Bangladesh
}

\author{
ROY NR ${ }^{1}, K^{\prime} H A N M R K^{2}$, MIAH MBA ${ }^{3}$, ISLAM MR ${ }^{4}$, MAJUMDER $B^{5}$, DAS $S^{6}$, \\ UDDIN MK ${ }^{7}$, HAQUE MA ${ }^{8}$, SARKER $I^{9}$
}

\begin{abstract}
:
Background: $A D$ is the most common cause of dementia in elderly which causes economic burden for the affected individual, caregivers and society. The objective of this study was to see demographic characteristics among $A D$ patients and it will provide magnitude of the problem and planning of health programme for prevention of disease. Methods: This observational analytical study was carried out in the Neurology ward, OPD and Dementia clinic of BSMMU, Dhaka from May' 15 to February' 17. A total of 45 patients were recruited as study population after satisfying all the criteria for enrollment. Results: A total of 27 male and 18 female with mean age of $69.20 \pm 11.16$ years, constituted as cases. Conclusion: The occurrence of $A D$ found more after the age of 65 years. The present study found that lower educational level is associated with more chance of getting AD. Higher rate of Alzheimer's disease was found in older man than women.
\end{abstract}

Keywords: Dementia, Alzheimer's Disease, Demographic characteristics etc.

Introduction:

Alzheimer's disease (AD) is a specific neurodegenerative disease and is the most common cause of dementia in old people. Clinically, it is characterized by loss of memory, inability to learn new things, loss of language function, a deranged perception of space, inability to do calculations, indifference, depression, delusions, and other manifestations. These deficits affect patients' social functioning and make it difficult or impossible for them to carry on with daily living. $A D$ is relentlessly progressive and fatal within 5 to 10 years. $A D$ patients usually die of complications of chronic illness. $A D$ is the fourth to fifth most common cause of death in the United States. Sometimes AD involves people in their 40 s and $50 \mathrm{~s}$, but is mainly a disease of old age. It's incidence is 1.2 per 1000 person years among 65-69-years, increasing to 53.5 in those $>90$ years and prevalence is $4.4 \%$ in those
$>65$ years. Affects females more than males; most common $>65$ years ${ }^{1}$.

With the exception of cases of Alzheimer's caused by genetic abnormalities, experts believe that Alzheimer's, like other common chronic diseases, develops as a result of multiple factors rather than a single cause. The greatest risk factors for lateonset "sporadic" Alzheimer's are older age ${ }^{2}$, having a family history of Alzheimer's ${ }^{3}$ and carrying the APOE-e4 gene ${ }^{4}$. Several studies on Alzheimer's disease and other types of dementia in different countries and continents have shown a steady increase in the incidence of dementia according to age and Alzheimer's disease is the main cause ${ }^{5}$. Several risk factors of dementia and Alzheimer's disease have been studied, sex is one of them. Female sex found affecting more than male. Previous prevalence surveys also found an increased risk among women ${ }^{6}$.

1. Dr. Niloy Ranjan Roy, Indoor Medical Officer, Dept. of Neurology, DMCH, Dhaka.

2. Prof. Md. Rezaul Karim Khan, Ex. Chairman, Dept. of Neurology, BSMMU, Dhaka.

3. Dr. Md. Bahadur Ali Miah, Associate Professor, Dept. of Neurology, BSMMU, Dhaka.

4. Prof. (Dr.) Md. Rafiqul Islam, Chairman, Dept. of Neurology, BSMMU, Dhaka

5. Dr. Bipasha Majumder, MO, Dept. of Laboratory Medicine, DMCH, Dhaka.

6. Dr. Saumitra Das, Biochemist, Dept. of Biochemistry, Cumilla Medical College.

7. Mohammad Kafil Uddin, Resident (Phase- B), Dept. of Neurology, BSMMU, Dhaka.

8. Dr. Md. Azizul Haque, Medical officer. UHC, Nandigram, Bogura.

9. Dr. Imran Sarker, Assistant Professor (CC), Dept. of Clinical Neurology, NINS\&H, Dhaka. 
People with fewer years of formal education are at higher risk for Alzheimer's and other dementias than those with more years of formal education ${ }^{7}$. The effect of education on the risk of dementia and Alzheimer's disease is still controversial. Several studies have reported an increased prevalence of Alzheimer's disease in poorly educated people ${ }^{8}$, but several case-control or population based studies failed to confirm this association ${ }^{9}$. A higher incidence of Alzheimer's disease was found among subjects in the North Manhattan (New York) Study who had less than 8 years of education ${ }^{10}$. The aims and objectives of this study were to see demographic variations among the Alzheimer's disease patients.

\section{Methods:}

This observational analytical study was conducted in Neurology ward, OPD and Dementia clinic (besides general OPD services of neurology, there are six specialized clinics are running for patients of specific neurological diseases. Dementia clinic is one of them, where only patients of dementia are evaluated and managed by neurology consultants. This clinic provides service to the patients every Thursday from 11 am to $2: 30 \mathrm{pm}$. About 20-30 patients per month are getting services from this clinic. Proper registrar is maintained in the Dementia clinic for research purpose of BSMMU, Dhaka during May' 15 to February' 17. All adult consecutive patients with clinical diagnosis of Alzheimer's disease at the place of study were study population. After ethical clearance from Institutional Review Board (IRB), patients having features of $A D$ according to revised NINCDSADRDA criteria ${ }^{11}$ were selected. Informed written consent was taken from each patient or his/her attendants. After taking proper history, physical, neurological examination including MMSE were done. The cognitive impairment was assessed by MMSE$^{12}$ score (Mild 20-24, Moderate 10-19, Severe $<10$ ). Relevant investigations including MRI of brain were done to diagnose $A D$ and rule out other causes of dementia. 45 patients were taken as cases after satisfying all the criteria for enrollment. All data were recorded in semi structured data sheet. A semi-structured questionnaire was developed in English for recording of data and MMSE sheet was translated in Bengali version.

\section{Results:}

The study included 45 Alzheimer's disease patients. Table $-I$ shows that the mean age of $A D$ patients was $69.20( \pm 11.16)$ years.

\section{Table-I}

Distribution of the study population by age groups ( $N=45)$.

\begin{tabular}{lcc}
\hline Age (year) & Case $(n=45)$ & Percent \\
\hline $45-54$ & 03 & $6 \%$ \\
$55-64$ & 13 & $29 \%$ \\
$65-74$ & 15 & $33 \%$ \\
$\geq 75$ & 14 & $31 \%$ \\
\hline
\end{tabular}

Table-II

Distribution of the study population by gender $(N=90)$.

\begin{tabular}{lcc}
\hline Gender & Case $(\mathrm{N}-45)$ & Percent \\
\hline Female & 18 & $(40)$ \\
Male & 27 & $(60)$ \\
\hline
\end{tabular}

Table -II shows that among 45 AD patients $40 \%$ were female and $60 \%$ male.

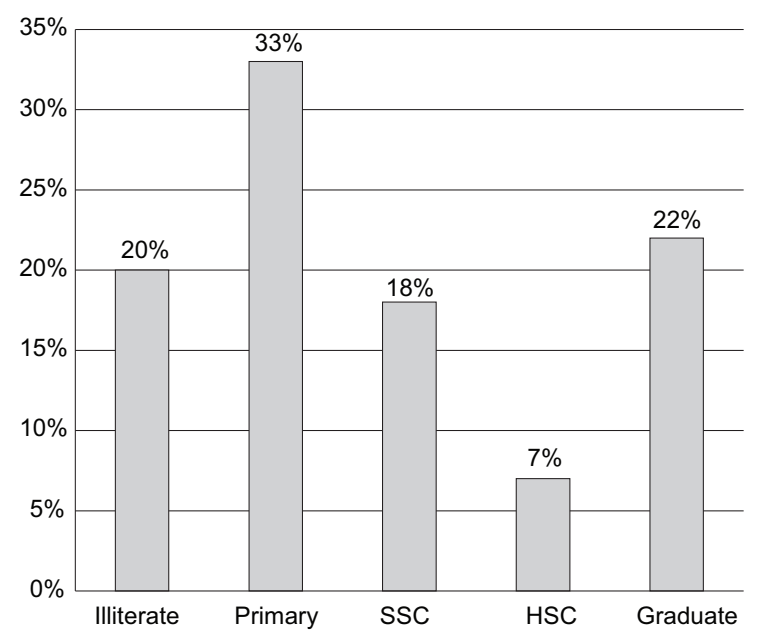

Fig.-1: Bar diagram showing educational level of Alzheimer's disease patients $(\mathrm{N}=45)$.

Figure-1 shows distribution of Alzheimer's disease patients according to educational level. Among all 
the patients, a major portion of study population was taking primary education accounting $33 \%$ which is closely followed by graduation $22 . \%$ and illiteracy $20 \%$ in case group. $71 \%$ AD patients belongs to lower educational level (Illiterate up to SSC).

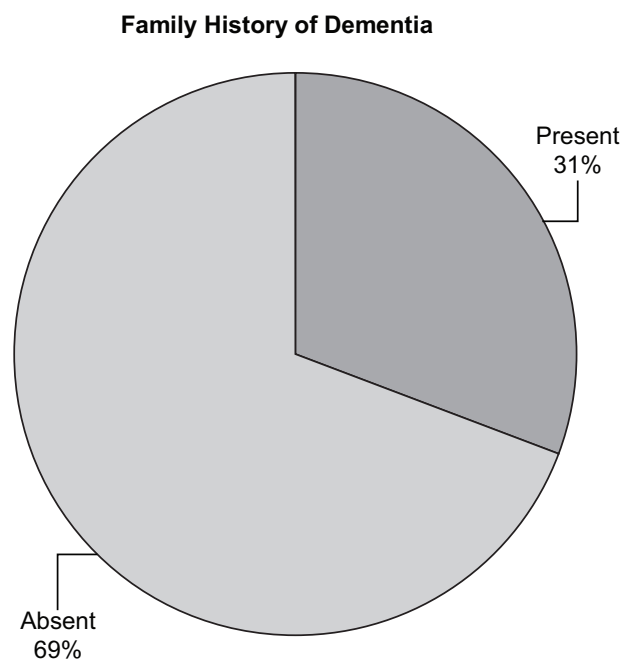

Fig.-2: Pie chart showing Family history of dementia present in $A D$ patients (N-45).

Figure-2 shows that family history of dementia was present in $31 \% \mathrm{AD}$ patients.

\section{Table-III}

Distribution of the co morbid disease of Alzheimer's disease patients ( $N=45)$.

\begin{tabular}{lc}
\hline Diseases accompanying & $\begin{array}{c}\text { Number of } \\
\text { patients }\end{array}$ \\
\hline DM patients & 31 \\
HTN & 49 \\
CKD & 29 \\
Dyslipidaemia & 47 \\
IHD & 13 \\
\hline
\end{tabular}

Table III: shows 49 patients were hypertensive, 47 patients were suffering from dyslipidaemia, 31 patients were diabetic, 29 patients were suffering from CKD, 13 patients were suffering from IHD.

\section{Discussion:}

In this study analysis of age distribution showed that, the mean age of Alzheimer's disease patients was [69.20 ( \pm 11.16$)]$ years. It coincides with studies like $13,14,15$ but age group seemed to be higher in comparison to this study. It might be due to lower life expectancy of peoples in our country. There was male preponderance, $60 \%(27)$ were male and $40 \%$ (18) were female. It was consistent with studies like ${ }^{13,17}$ but does not coincide with studies like ${ }^{14,15,18,19}$. In context of our country, lower proportion of female patients were enrolled in this study may be due to less preference for females for seeking medical attention. Among all the patients, a major portion of study population had the primary education accounting $33 \%$, which is closely followed by graduation $22 . \%$ and illiteracy $20 \%$ in case group. $71 \%$ AD patients belongs to lower educational level (Illiterate upto SSC). It coincides with studies like ${ }^{20,21}$ where they found an association between low educational level and higher risk of developing AD. A significant number of $A D$ patients $(22 \%)$ completed graduation as because patients and their family members are more concern for seeking medical attention.

Family history of dementia was present in $31 \%$ in the AD patients. Outpatient department of neurology BSMMU runs a separate weekly dementia clinic where dementia patients attended. Most of the patients presented with moderate dementia $(60 \%)$ and the rest had the severe dementia (29\%) and mild dementia (11\%).

\section{Conclusion:}

$A D$ patients found more after 65 yrs. Higher rate of $A D$ was found in older man. Lower educated people affected more than higher educated.

\section{References :}

1. Manji H, Kitchen N, Lambert C, Mehta A. Oxford Handbook of neurology. $3^{\text {rd }}$ ed. United kingdom: Oxford University press; 2014. 202

2. Hebert LE, Weuve J, Scherr PA, Evans DA. Alzheimer disease in the United States (20102050) estimated using the 2010 Census. Neurology. 2013; 80(19): 1778-83.

3. Green, R.C., Cupples, L.A., Go, R., Benke, K.S., Edeki, T. and Griffith, P.A. Risk of dementia among white and African American relatives of patients with Alzheimer disease. The Journal of the American Medical association. 2002; 287(3): 329-36. 
4. Farrer LA, Cupples LA, Haines JL, Hyman B, Kukull WA, Mayeux R. Effects of age, sex, and ethnicity on the association between apolipoprotein $\mathrm{E}$ genotype and Alzheimer disease: A meta-analysis. The Journal of the American Medical association. 1997; 278(16): 1349-56.

5. Miriam K, Aronson EdD, Wee L, Ooi DrPH, Dalia L, Geva, et al. Age-Dependent

6. Incidence, Prevalence, and Mortality in the Old. Arch Intern Med. 1991;151(5): 989-992.

7. Jorm AF, Korten AE, Henderson AS. The prevalence of dementia: a quantitative integration of the literature. Acta Psychiatr Scand. 1987;76: 465-79.

8. Stern Y. Cognitive reserve in ageing and Alzheimer's disease. The Lancet Neurology. 2012; 11(11): 1006-12.

9. Katzman R. Education and the prevalence of dementia and Alzheimer's disease. Neurology. 1993; 43:13-20.

10. Beard M, Kokmen E, Offord K, et al. Lack of association between Alzheimer's disease and education, occupation, marital status or living arrangement. Neurology. 1992; 42: 2063-8.

11. Stern Y, Gurland B, Tatamichi TK, et al. Influence of education and occupation on

12. the incidence of Alzheimer's disease. JAMA. 1994; 271: 1004-10.

13. Dubois B, Feldman H., Jacova C, Dekoski S, Barber-Gateau P. Cummings J. Research criteria for the diagnosis of Alzheimer's disease: revising the NINCDS-ADRDA criteria. Lancet Neurology. 2007; 6(8): 734-46.

14. Folstein MF, Folstein SE, McHugh PR.. Minimental state. A practical method for grading the cognitive state of patients for the clinician. Journal of Psychiatric Research. 1975; 12 (3): 189-98.

15. Talebi M, Farhodi M, Nikanfar M, Majidi J. Fakhari A. Study on serum homocysteine level in Alzheimer's disease and its relationship with the stages of this disease. Neurosciences. 2008; 13(4) : 359-62.

16. Koseoglu E, Karaman Y. Relations between homocysteine, folate and vitamin B12 in vascular dementia and in Alzheimer disease. Clinical Biochemistry. 2007; 40(12): 859-863.

17. Quadri P, Fragiacomo C, Pezzati R. Homocysteine, folate, and vitamin B12 in mild cognitive impairment, Alzheimer disease and vascular Dementia. The American Journal of Clinical Nutrition. 2004; 80(1): 114 -22.

18. Leblhuber F, Walli J, Artner-Dworzak E, Vrecko K, Widner B. Reibnegger G. Hyperhomocysteinemia in dementia. Journal of Neural Transmission. 2001; 07(12): 1469-74.

19. Karimi F, Haghighi AB, Petramfar P. Serum Levels of Homocysteine, Vitamin B12 and Folic Acid in Patients with Alzheimer's Disease. Iranian Journal of Medical Science 2009; 34(3) :181-85

20. Chen H, Liu S, Ji L, Wu T, Ma F, Ji Y. Associations between Alzheimer's Disease and Blood Homocysteine, Vitamin B12 and Folate: A Case-Control Study. Current Alzheimer Research 2015; 12(1): 88-94.

21. Clarke R., Smith, A.D, Jobst K.A, Refsum H, Sutton L. Ueland PM. Folate, vitamin B12, and serum total homocysteine levels in confirmed Alzheimer disease. Archives of Neurology. 1998; 55(11):1449-55.

22. Letenneur L, Gilleron V, Commenges D, Helmer C, Orgogozo JM. Dartigues JF. Are sex and educational level independent predictors of dementia and Alzheimer's disease? Incidence data from the PAQUID project. J Neurol Neurosurg Psychiatry. 1999; 66:177-83.

23. Ott A, Breteler MMB, Harskamp Fv, Claus JJ, Cammen TJM, Grobbee DE et al. Prevalence of Alzheimer's disease and vascular dementia: association with education. The Rotterdam study. BMJ. 1995; 310: 970. 